\title{
How Powerful is Feedforward in University Education? A Case Study in Romanian Geography Education on Increasing Learning Efficiency
}

\author{
Maria Eliza Dulamă ${ }^{1}$ \\ Babeş-Bolyai University
}

\author{
Oana-Ramona Ilovan ${ }^{2}$ \\ Babess-Bolyai University
}

\begin{abstract}
There are different opinions about the meaning of feedforward: some consider it a response to feedback, while others think it consists of suggestions given to a person in order to help them before learning or starting a task. This study analyzed the professor's and university students' actions during a seminar activity with a group of 60 students from Babeş-Bolyai University in Cluj-Napoca, Romania and represented them in a flowchart. It also analyzed the efficiency of several didactic techniques and tools that were used with the role of feedforward (e.g., task, checklists). Students' results in the form of sketch maps were compared with the ones from a control group of another 60 students from the same university; the methods and tools that were used as feedforward were noticed to determine an increase in efficiency and better product quality. The feedforward categories were systemized and described, thus filling a gap in the literature of the field. To increase students' learning efficiency and the quality of their results, professors should use feedforward more than feedback, because this creates and ensures the necessary conditions for students to correctly solve tasks and to prevent them from making mistakes.
\end{abstract}

Keywords

Feedforward • Geography • Quality • Learning self-regulation • Assessment tool • Sketch map

\footnotetext{
1 Faculty of Psychology and Sciences of Education, Babeş-Bolyai University, Cluj-Napoca Romania. Email: dulama@upcmail.ro

2 Correspondence to: Oana-Ramona Ilovan (PhD), Faculty of Geography, Babeș-Bolyai University, 5-7 Clinicilor Street, Cluj-Napoca 400006 Romania. Email: ilovanoana@yahoo.com

Citation: Dulamă, M. E. \& Ilovan, O-R., (2016). How powerful is feedforward in university education? A case study in Romanian geography education on increasing learning efficiency. Educational Sciences: Theory \& Practice, 16, 827-848.
} 


\section{Theoretical Background}

Professors in the Romanian university system plan and organize their activities under the assumption that their students have the subject-specific competences mentioned in the school curricula for the geography class in the pre-university education system or from previous years of university studies. In reality, these students do not have all these competences developed at a superior level, and this is the reason they have difficulties when solving tasks. Frequently, professors notice this situation rather late, after students' involvement in the learning process. At this point, professors cannot change any results and are only able to offer feedback (Cathcart, Greer, \& Neale, 2014).

In order to prevent students from failing and to fill in the gap between students' necessary knowledge or the competences that professors expect and the real ones that professors actually use, there are diverse educational tools beside the ones from their pedagogical discourse: tests, questionnaires, checklists, worksheets, study guides, instructions, protocols, tutorials, examples, glossaries, and so on. When planning activities and educational tools, professors should anticipate students' problems when learning and should find appropriate ways to formatively intervene. In order to solve the problem by increasing students' success rate and diminishing failure, this study looked for the best educational mechanisms and tools for professors to use during their students' learning process during courses and seminars as well as apart from these formal activities, not after students have finished learning. Some researchers consider feedforward to be such a prevention mechanism (Baker \& Zuvela, 2013; Cathcart et al., 2014; Goldsmith, 2008), but opinions about how to use it differ (Duncan, 2007; Gibbs \& Simpson, 2004; Hernández, 2012; Koen, Bitzer, \& Beets, 2012; Murtagh \& Baker, 2009).

During activities, professors often empirically use both feedback and feedforward. In opposition to feedback, feedforward is a controversial subject that has been paid little attention in educational research. So that professors are able to use feedforward from a scientific perspective, this study performs an exploratory research by finding proof for the use of feedforward in comparison with feedback; it also utilizes a quasi-experimental research to test certain tools with a feedforward role. Direct observation, documents, and findings were observed in order to draw a series of theoretical conclusions about feedforward.

Understanding and explaining feedforward has been enabled through a series of studies on feedback that focused on presenting the concept (Hattie \& Timperley, 2007; Higgins, Hartley, \& Skelton, 2001; Lyster \& Ranta, 1997), its importance during learning (Brown, 2004; Brown, Harris, \& Harnett, 2012; Clarke, 2003; Hattie \& Timperley, 2007; Pajares \& Graham, 1998), the receiver (Higgins et al., 2001; 
Irving, Harris, \& Peterson, 2011; Wiggins, 2004), the feedback source (Brown et al., 2012; Peterson \& Irving, 2008; Topping, 2010), administration conditions (Brown et al., 2012; Hattie \& Timperley, 2007), the moment of giving feedback (Hattie \& Timperley, 2007), the methods of giving it (Koen et al., 2012), typology (Fink, 2007; Harris, Brown, \& Harnett, 2014; Hattie \& Timperley, 2007; Irving et al., 2011; Mori, 2011; Murtagh \& Baker, 2009; Shute, 2008), its impact (Brown, 2004; Gibbs \& Simpson, 2004; Koen et al., 2012), and its efficiency (Akalin \& Sucuoglu, 2015; Hattie \& Timperley, 2007; Irving et al., 2011; Shute, 2008; Topping, 2010).

The neurosciences have frequently researched feedforward using feedforward to trigger: visually selective behavior (Van Rullen \& Koch, 2003), the learning capability and storage capacity of feedforward networks (Huang, 2003), and the changes in feedforward postural adjustments following voluntary motor training (Tsao \& Hodges, 2007). In lightwave technology, they have researched coherent optical communications that use feedforward architecture (Ip \& Kahn, 2007). Other studies have focused on using feedback and feedforward for scheduling control tasks (Cervin, Eker, Bernhardsson, \& Årzén, 2002).

Few studies are found about using feedforward in education (Duncan, 2007; Goldsmith, 2008), and researchers have frequently approached it alongside feedback (Gibbs \& Simpson, 2004; Hernández, 2012; Koen et al., 2012; Murtagh \& Baker, 2009). Feedforward has two meanings. The first one refers to learners' actions and is described as "a concept that focuses on the responses of learners to feedback" (Hernández, 2012, p. 492). Lyster and Ranta (1997) named students' prompt response to professor's feedback as assimilation, similar to what other researchers have named feedforward (Duncan, 2007; Gibbs \& Simpson, 2004; Hernández, 2012; Koen et al., 2012; Murtagh \& Baker, 2009). Moreover, the "feedforward assessment implies that students recognize the goal of feedback and interpret and apply the suggestions in order to close the gap between the current level of performance and the expected learning objective" (Koen et al., 2012, p. 240).

The second sense underlines that feedforward refers to the actions of a person who gives future suggestions to somebody else because these can significantly help the other person and because this person should learn as much as possible (Goldsmith, 2008 , p. 2). Moreover, feedforward provides students with prior exposure to assessment and thus helps clarify professors' expectations and standards (Baker \& Zuvela, 2013). In addition, in comparing feedback with feedforward, Goldsmith underlined several features of the latter: it focuses on the future, not the past; "it is almost always seen positively because it focuses on solutions," to solving tasks, not on correcting mistakes; "it cannot involve a personal critique, as it discusses something that has not yet happened;" "it can reinforce the possibility of change" (2008, p. 3); 
"it does not imply superiority of judgment;" and "it tends to be much faster and more efficient than feedback" (2008, p. 4). By giving different meanings to the concept of feedforward in reference to its source (learner vs. teacher or the one directing the learning) or its function (direct connection vs. response to feedback), one can determine its misunderstandings and low capitalization of learning. Because "improving the quality of education depends on the performance of teachers" (Şencan \& Karabul, 2015, p. 359; Vávra, 2014) in the positive emotional sphere, in active participation, and in building upon the experience of the classroom (Klonari \& Mandrikas, 2014, p. 149), teachers should understand and use feedforward appropriately. By using feedforward, students also can have the opportunity to develop their future visions as they become active (Artvinli, 2010a). In such a learning-teaching environment, teachers can influence the way their students learn and stimulate active learning (Artvinli, 2012) based on constructivist theories (Artvinli, 2010b).

To understand in depth the way to use feedforward as an educational tool, our aim is to answer the following question: How can one determine an increase in learning efficiency during activities with students and an increase in the quality of results when using feedforward? Out of this essential question, a series of other secondary questions result: What is feedforward? Who needs it? Who should offer it? Why should anyone offer it? When should one offer it? What should it contain? How does one build feedback? What are the methods, techniques, and tools through which one can offer it? What are its features? What are its categories? How do students regulate their activity according to the feedforward? What is its impact? And, what are the limits?

In order to research feedforward and to answer these questions, a naturalist paradigm was used to analyze the professor's and students' actions during a seminar activity. During this activity, the focus was shifted from the feedback to feedforward method, as suggested by Higgins et al. (2001), to help students solve tasks according to the professor's expectations. At the end of the activity, students' actions were analyzed and interpreted to identify the effects of the employed feedforward techniques and tools. In the end, the research findings and elaborated models underlined the manner in which professors could determine how to utilize feedforward to increase learning efficiency and the quality of their students' results.

\section{Method}

\section{Design}

This quasi-experimental activity took place in 2015 during a two-hour seminar for the Geography and Teaching Geography in Primary Grades and Kindergarten Class at the specialisation the Pedagogy of the Primary Grades and Kindergarten Education at the Faculty of Psychology and Sciences of Education from Babeş-Bolyai University in Cluj-Napoca, 
Romania. The learning objectives (to perceive correctly the geographical space represented on maps and to learn a method of representing landforms), the task (individual drawing of a sketch map), and the process stages to be undergone (studying the atlas map, the text, and the model sketch; representing the mountainous units, the valleys, the rivers; writing the names, title, and sketch orientation; and elaborating the legend) were communicated to both groups, the experimental group (EG) and the control group (CG). Students received the written text of the task for rereading, maps, a monochrome model sketch of the terrain from the textbook (Dulamă, 2011, p. 91), and the text for the Task Variant 1 (V1; see Table 1). Task V1 included 12 written commands in the logical order students should perform them, and they were correlated with nine indicators (I) from the assessment tool (I1-I25).

Students in the EG also benefited from the professor's feedforward interventions while they solved the task. They received Checklist 1 at the end of the activity in order to monitor task solving. After the activity, Task Variant 2 (V2) and Checklist 2 (see Table 2) were e-mailed to the students, as both instruments had been improved after the seminar. They used Checklist 2 at home to monitor their solutions to the task.

\section{Population}

Included in this research were 120 third-year prospective primary-school and kindergarten teacher university students. Simple randomization was used to form two groups, an experimental and a control group of 60 students each, to represent two seminar groups. These students represented a sample of the population with similar features. They had not solved the researched task before. Under the circumstances of anonymity and privacy, students volunteered to participate in the research and to have their projects used during the research. Students perceived the primary author of this paper as a professor, not as a researcher, which helped to ensure the authenticity of students' actions and the interventions. However, this could have induced a certain degree of subjectivity. The heterogeneity of groups according to gender and age was not relevant to this research, but their knowledge level and competence in geography might have influenced the research findings and its generalizability. As this quasiexperimental study took into account only one faculty and a small number of subjects, it is possible that statistical data do not represent any student population or sample from the respective field of specialization; some of the conclusions might be limited.

\section{Data Collection and Processing}

For collecting behavioral (professor and student actions in the EG) and verbal (professor and student assertions, questions, and answers in the EG) data during the seminar, the participatory observation method and an observation sheet were used. The behavioral data is presented in Figure 1. A qualitative analysis of verbal data was performed through a systematic study of the conversation organization. 
The 120 sketch maps from the students in the two work groups were assessed, and simple randomization was used for choosing which ones to elect for assessment through an analytical assessment tool with a dichotomous scale (Table 5). Researchers have used grids, such as in Table 5, to identify mistakes in column charts (OsaciCostache, Dulamă, \& Ilovan, 2013b) and in touristic plans (Osaci-Costache, Dulamă, Alexandru, \& Voitovici, 2013) for assessing the level of competence when elaborating topographical profiles (Osaci-Costache, Dulamă, \& Ilovan, 2013a) or when elaborating choropleth maps combined with diagram maps (Osaci-Costache, Cucoş, \& Cucoş, 2015). The method of content analysis, which is useful for assessment, was used (Dulamă \& Ilovan, 2015). The tool included six assessment criteria and 25 indicators correlated to the questions from Checklist 2. In comparison to the tools in the published research that have been presented so far, whereas researchers had awarded a certain score for each criterion, 2 points were awarded for each correct representation correlated to a certain indicator, 1 point for a partially correct representation, and 0 points for an incorrect representation or one lacking its respective element. One sketch map could be awarded with a minimum of 0 points and a maximum of 50 points (range being 50), and a minimum of 0 mistakes and a maximum of 25 (range being 25).

Data processing used descriptive statistics. The total number and the mean number of points for each paper, the total number of mistakes and deficiencies, as well as their mean value, were computed using this method. For each indicator and for each group, the total number of points and the mean value were computed, as were the total number of mistakes and deficiencies. In order to test the differences of means for the map scores and the errors between the two groups, the independent sample $t$-test was used. In addition, in order to have a qualitative interpretation of the magnitude of differences between groups, the effect size of each comparison was computed in term of Cohen's $d$ (the standardized difference between the means).

In this research, it was important that the research tool had content validity because the indicators associated with the assessment criteria showed the quantitative and qualitative representation of all components in the sketch maps and ensured objectivity of assessment. Moreover, it was relevant that this tool had construct validity because it included the essential features of the concept of map: "a precise, generalized, reduced, conventional, graphic representation of a terrestrial surface on a plane surface which shows the interdependency between the natural and social phenomena at a certain moment" (Osaci-Costache, 2008, p. 73). As opposed to maps, sketch maps do not have to be precise. The difficulty coefficient that was computed for each indicator and for all students varied between $13.33 \%$ and $91.67 \%$. For three indicators, the percentage was below $25 \%$, but they were not eliminated because the assessed aspects (i.e., peaks, depressions, rivers) were essential for representing the landforms. This coefficient showed where students had greater difficulties and needed feedforward. 


\section{Research Material}

In order to answer the research questions about feedforward, the following were analyzed and interpreted: professor's products (Tasks 1 and 2, Checklists 1 and 2, and the assessment tool of the sketch maps that students realized [presented in Table 3]), behavioral data (professor's and EG students' actions during the seminar [Figure 1]) and verbal data (professor's and EG students' assertions, questions, and answers) that were written on the observation sheet, and the students' results (i.e., sketch maps [Tables $3 \& 4$, and Figure 2]).

\section{Findings}

The following material presents the professor's products, professor's and students' actions in the EG, and students' results. Task V1 (Table 1), having the role of feedforward, included 12 commands and correlated with nine indicators (36\% of the total) from the assessment tool. The phrasing of Task V2 was improved with 23 more pieces of information, which reached 32 commands and correlated to 14 indicators (56\%) from the assessment tool, 5 more indicators compared to Task V1 (an additional 20\%).

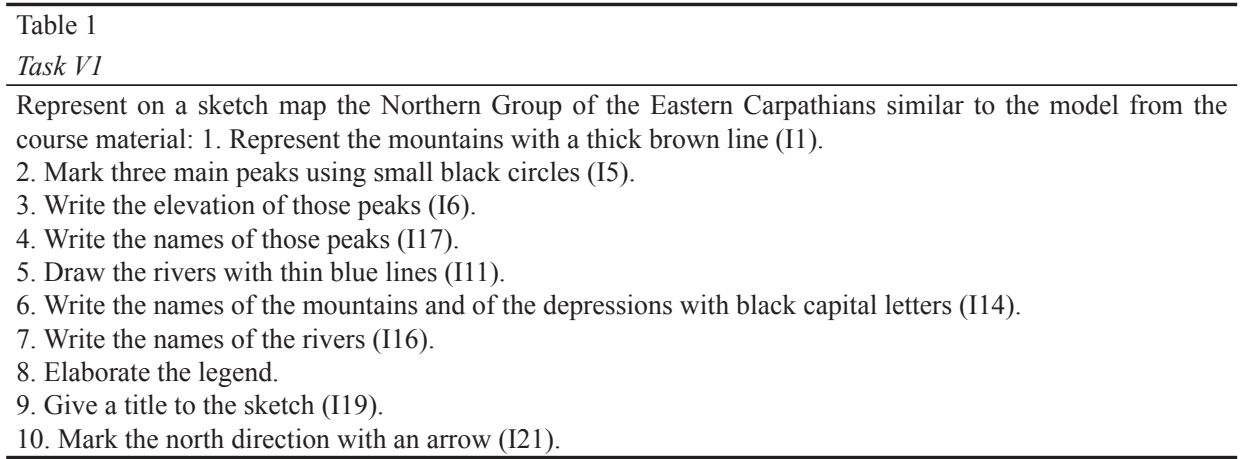

Checklist 1 has 16 questions correlated to 12 indicators from the assessment tool ( $48 \%$ of the total), which is 3 indicators more than in task V1. Because of space restrictions, it has not been included, but its content is visible through the regular font style (italics excluded) in Checklist 2.

Checklist 2 includes 31 questions correlated with 14 indicators, similar to Task V2 (56\%). It also includes 13 questions which were not correlated to the indicators but were useful for task solving. Out of the four tools, Checklist 2 has the most pieces of information correlated to the indicators. Task V2, because of space restrictions, has not been included in this paper. However, the content of Checklist 2 offers information about its content. 
Table 2

Checklist 2

1. Did you place the A4 format paper in a landscape position?

2. Did you place the sketch in the centre of the sheet of paper?

3. Did you leave enough space for the title and legend?

4. Did you take into account the size of the mountainous group in the E-W and N-S directions so that the sketch would be similar to the size on the map?

5. Did you draw the $1 \mathrm{~mm}$ thick brown lines oriented along the main crest of each mountain and long enough in order to replicate its reality? (I1)

6. Did you draw the brown lines by uniting the main peaks and taking into account the watershed, so that the rivers flow from the crest towards different directions?

7. Did you write the names of the mountains with black capital letters above the brown lines? (I14)

8. Did you abbreviate the word mountains to Mtn.?(I15)

9. Did you verify whether or not you had represented mountainous sub-units from other mountainous groups?

10. Did you represent three main peaks with small black circles? (I5)

11. Did you abbreviate the word vârf (peak) to Vf. (this abbreviation is specific to the original Romanian)? (I15)

12. Did you write the height of the peaks? (I6)

13. Did you write the names of the peaks with small-sized letters? (I17)

14. Did you abbreviate the word depression to Dep.? (I15)

15. Did you write the names of the depressions with black capital letters? (I14)

16. Did you circle the area of depressions with a thin line? (I9)

17. Did you take into account the lower height of depressions in comparison with that of the mountains?

18. Did you color the area of depressions in yellow? (I9)

19. Did you verify whether or not you had represented depressions from other mountainous groups?

20. Did you draw the rivers with thin blue lines between the mountainous units where they flowed in reality? (I11)

21. Did you write the names of the rivers with small blue letters? (I16)

22. Did you observe the direction of river flow from higher altitudes to lower ones?

23. Did you take into account the place where each main river sprang from and where it met with other rivers?

24. Did you write the name of the mountainous group in the upper part of your sheet of paper? (I20)

25. Did you mark North with an arrow crossing the middle of the letter N? (I21)

26. Did you elaborate the legend in the lower part of your sheet of paper?

27. Did you write the title of the legend with capital letters? (I22)

28. Did you represent in the left part of the legend all the symbols you used in the sketch? (I23)

29. Did you align the symbols one below the other?

30. Did you mention the significance of the symbols through plural nouns that began with a capital letter? (I25)

31. Did you align the explanatory words in the legend one below the other?

In Figure 1, what the professor realized as the four main actions (PA 1-4) has been emphasized; the first three were direct actions oriented towards the group and received by each student, while the fourth one was indirect and focused on assessing products during students' absence.

The professor realized four direct secondary actions (PA 2a, 2b; PA 3a, 3b) that targeted all students with the function of feedback and feedforward through which she regulated teaching and learning. The professor had seven reactions to students' actions (PR 1a, 1b, 1c; PR 2a, 2b, 2c, 2d, 2e). Students realized five main actions with the feedback function (SR 1-6) and nine secondary actions (SR 1a, 1b, 1c; SR $2 \mathrm{a}, 2 \mathrm{~b}, 2 \mathrm{c} ; \mathrm{SR} 4 \mathrm{a}, 4 \mathrm{~b}, 4 \mathrm{c})$. Some of the professor's main actions were accompanied by feedforward (communicating the task; supervising the solution process) or by feedback (final assessment); others had the feedforward function (students were offered the checklist). The professor received silent or spoken feedback four times from her students; she offered spoken feedback to her students five times, and she 


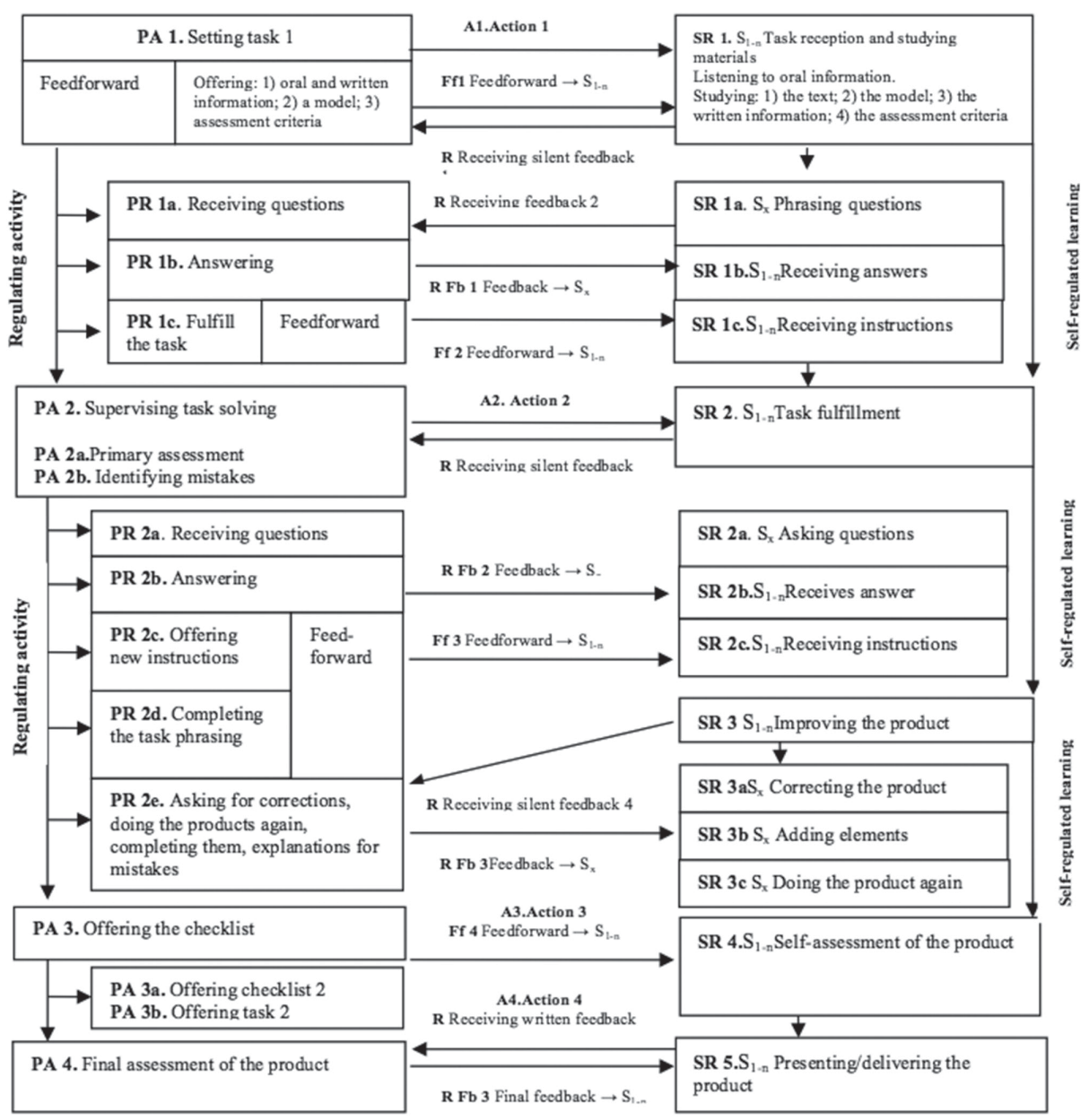

Figure 1. Professor's and Students' Actions in the EG (PA-professor's action; PR-professor's reaction; SR-students' reaction; Fbfeedback; Ff-feedforward; R- reaction; $S_{1-n}$-all students; $S_{x}$ - any student in the group).

offered them spoken feedforward four times. The students offered and asked for feedback, responded to the professor's feedback and feedforward, and self-regulated their learning.

The results (Table 3) show that the EG recorded a higher mean of map scores $(\mathrm{M}=38.20, \mathrm{SD}=5.56)$ than the $\mathrm{CG}(\mathrm{M}=31.05, \mathrm{SD}=7.90)$, with a statistically significant difference, $t(118)=5.71, \mathrm{p}<.001$, and with a large effect size, $d=1.04$. Also, analysis proved that the $\mathrm{EG}$ recorded a smaller mean of map errors, $(\mathrm{M}=3.61, \mathrm{SD}=2.59)$ than the $\mathrm{CG}(\mathrm{M}=5.98, \mathrm{SD}=3.76)$, with a statistically significant difference, $\mathrm{t}(118)=-3.99$, $\mathrm{p}<.001$, and with a moderate to large effect size $(d=-0.73)$. 


\begin{tabular}{ccccc}
\hline $\begin{array}{l}\text { Table 3 } \\
\text { Students'Results }\end{array}$ & & & \\
\hline Variables & Groups & $\mathrm{N}$ & Mean & SD \\
\hline Map scores & & & & \\
& Experimental group & 60 & 38.20 & 5.56 \\
& Control group & 60 & 31.05 & 7.90 \\
Map errors & & & & \\
& Experimental group & 60 & 3.61 & 2.59 \\
& Control group & 60 & 5.98 & 3.76 \\
\hline
\end{tabular}

\begin{tabular}{|c|c|c|c|c|c|c|c|c|}
\hline \multicolumn{9}{|c|}{$\begin{array}{l}\text { Table } 4 \\
\text { Assessment Tool and the Results Obtained from it }\end{array}$} \\
\hline \multirow{2}{*}{$\begin{array}{l}\text { Assessment } \\
\text { criteria }\end{array}$} & \multirow[t]{2}{*}{ 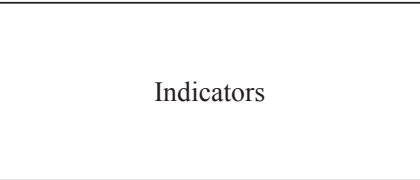 } & \multicolumn{2}{|c|}{$\begin{array}{l}\text { Mean } \\
\text { values for } \\
\text { scores }\end{array}$} & \multicolumn{2}{|c|}{$\begin{array}{l}\text { Mean } \\
\text { values for } \\
\text { mistakes }\end{array}$} & \multicolumn{3}{|c|}{$\begin{array}{l}\text { Difficulty coefficient } \\
\text { (\%) }\end{array}$} \\
\hline & & EG & CG & EG & CG & EG & CG & $\begin{array}{l}\text { Mean value } \\
(\mathrm{EG}+\mathrm{CG})\end{array}$ \\
\hline \multirow{7}{*}{$\begin{array}{l}\text { 1. Represent- } \\
\text { ing mountain- } \\
\text { ous units }\end{array}$} & $\begin{array}{l}\text { 1. Representing crests with thick } \\
\text { brown lines }\end{array}$ & 1.83 & 1.85 & 0.05 & 0.05 & 86.67 & 90.00 & 88.33 \\
\hline & 2. Length of crests & 1.60 & 1.28 & 0.00 & 0.03 & 60.00 & 35.00 & 47.50 \\
\hline & 3. Orientation of crests & 1.50 & 1.15 & 0.00 & 0.10 & 50.00 & 25.00 & 37.50 \\
\hline & $\begin{array}{l}\text { 4. Position of mountainous sub- } \\
\text { units within the landform unit }\end{array}$ & 1.63 & 0.97 & 0.00 & 0.25 & 63.33 & 21.67 & 42.50 \\
\hline & $\begin{array}{l}\text { 5. Representing peaks by using } \\
\text { symbols and placing the symbols on } \\
\text { the crest (interfluve) }\end{array}$ & 0.27 & 0.28 & 0.87 & 0.85 & 13.33 & 13.33 & 13.33 \\
\hline & $\begin{array}{l}\text { 6. Representing the height of peaks } \\
\text { (elevation) }\end{array}$ & 1.95 & 1.60 & 0.02 & 0.18 & 96.67 & 78.33 & 87.50 \\
\hline & $\begin{array}{l}\text { 7. Representing all mountainous } \\
\text { sub-units }\end{array}$ & 1.78 & 1.40 & 0.00 & 0.00 & 76.67 & 40.00 & 58.33 \\
\hline \multirow{3}{*}{$\begin{array}{l}\text { 2. Represent- } \\
\text { ing depressions }\end{array}$} & 8. Representing all depressions & 1.48 & 1.18 & 0.00 & 0.08 & 48.33 & 26.67 & 37.50 \\
\hline & $\begin{array}{l}\text { 9. Coloring the area of depressions } \\
\text { in yellow }\end{array}$ & 1.62 & 0.77 & 0.17 & 0.62 & 80.00 & 38.33 & 59.17 \\
\hline & $\begin{array}{l}\text { 10. Placing depressions within the } \\
\text { landform unit }\end{array}$ & 1.38 & 0.75 & 0.03 & 0.28 & 41.67 & 5.00 & 23.33 \\
\hline \multirow{3}{*}{$\begin{array}{l}\text { 3. Represent- } \\
\text { ing rivers }\end{array}$} & $\begin{array}{l}\text { 11. Representing rivers through } \\
\text { symbols }\end{array}$ & 1.95 & 1.97 & 0.00 & 0.02 & 93.33 & 98.33 & 95.83 \\
\hline & 12. Representing river flow & 1.02 & 0.62 & 0.20 & 0.50 & 21.67 & 11.67 & 16.67 \\
\hline & 13. Representing all rivers & 1.72 & 1.55 & 0.00 & 0.02 & 71.67 & 56.67 & 64.17 \\
\hline \multirow{5}{*}{$\begin{array}{l}\text { 4. Writing } \\
\text { names and the } \\
\text { title }\end{array}$} & 14. Names of the landforms & 1.87 & 1.72 & 0.03 & 0.03 & 90.00 & 75.00 & 82.50 \\
\hline & 15. Abbreviations & 1.82 & 1.67 & 0.07 & 0.07 & 88.33 & 73.33 & 80.83 \\
\hline & 16. Names of the rivers & 1.52 & 1.20 & 0.12 & 0.18 & 63.33 & 38.33 & 50.83 \\
\hline & 17. Names of the peaks & 1.68 & 1.50 & 0.05 & 0.12 & 73.33 & 61.67 & 67.50 \\
\hline & 18. Correctness of names & 2.00 & 1.82 & 0.00 & 0.02 & 100.00 & 83.33 & 91.67 \\
\hline \multirow{3}{*}{$\begin{array}{l}\text { 5. Editing } \\
\text { elements }\end{array}$} & 19. Correctness of the sketch title & 1.88 & 1.33 & 0.03 & 0.22 & 93.33 & 53.33 & 73.33 \\
\hline & 20. Placement of the sketch title & 1.50 & 1.12 & 0.25 & 0.43 & 75.00 & 55.00 & 65.00 \\
\hline & 21. Indicating North & 1.43 & 0.77 & 0.28 & 0.62 & 71.67 & 38.33 & 55.00 \\
\hline \multirow{4}{*}{$\begin{array}{l}\text { 6. Realizing } \\
\text { the legend }\end{array}$} & 22. Legend title & 1.20 & 1.10 & 0.40 & 0.45 & 60.00 & 55.00 & 57.50 \\
\hline & 23. Inclusion of all used symbols & 1.20 & 1.12 & 0.35 & 0.35 & 55.00 & 46.67 & 50.83 \\
\hline & 24. Representing symbols & 1.17 & 1.05 & 0.35 & 0.35 & 51.67 & 40.00 & 45.83 \\
\hline & 25. Explanation of symbols & 1.20 & 1.12 & 0.35 & 0.35 & 55.00 & 46.67 & 50.83 \\
\hline
\end{tabular}




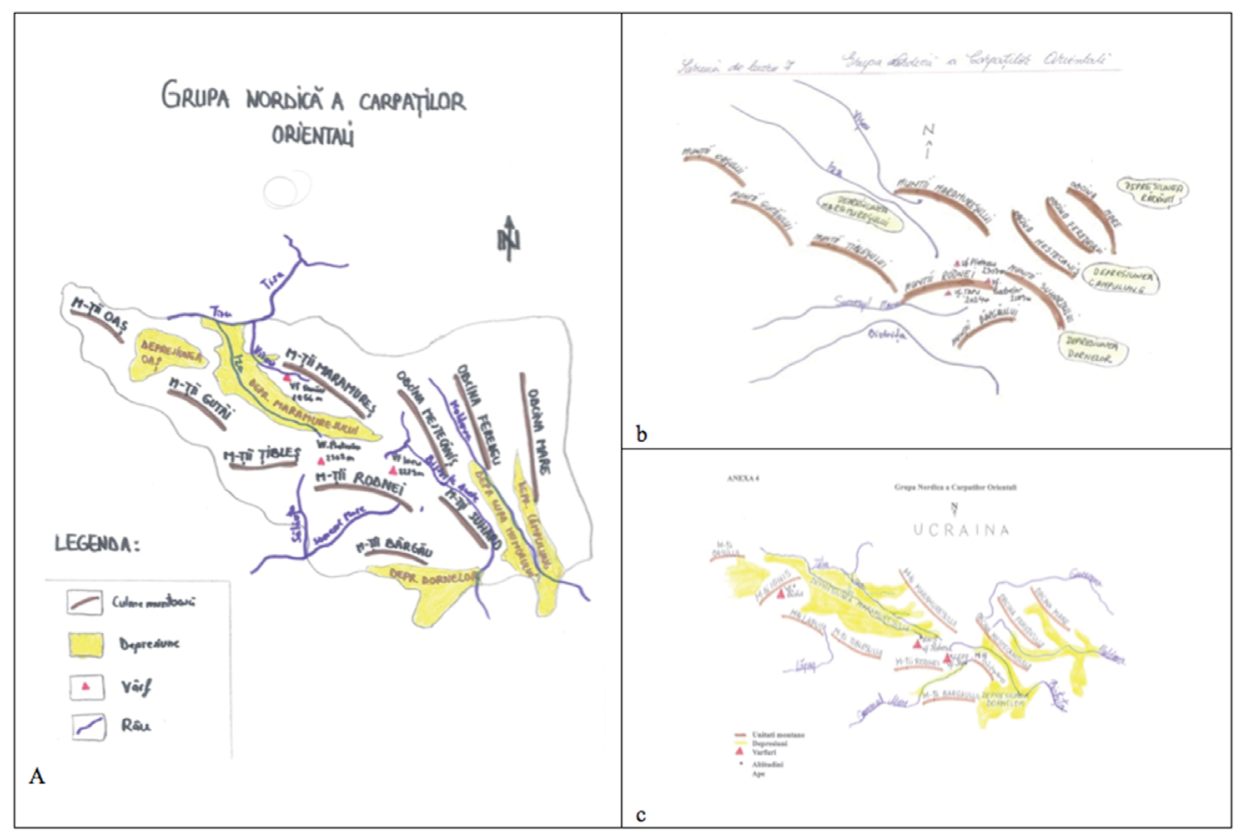

Figure 2. Sketch maps elaborated by students.

In analyzing the mean values according to indicators, the EG's significantly better results for 21 out of the 25 indicators from the assessment tool (Table 4) are emphasized. Both groups had low mean values for the criterion of elaborating the legend. The lowest and the highest mean values for the mistakes were for the indicator representing the peaks by using symbols and placing the symbols on the crest. The EG had a mean of 2 for the correctness of names, and the CG had the highest mean value (1.85) for representing the crests. The EG had a mean value of 0 for eight indicators, in contrast to the $\mathrm{CG}$ whose mean values were all above 0 .

In the sketch maps in Figure 2 (all of which contain some mistake or deficiency), the mountain peaks are represented near the crest, thus showing that students did not have correct representations of the peak and interfluve. In Figure 2b, the representation of the river flows of the Vişeu and the Iza between the crest and the depression is proof that the respective student did not know the significance of these concepts nor the fact that water flows to the lowest elevation point located within the depression.

\section{Discussions}

Next, the professor's and students' actions in the EG are analyzed and interpreted.

\section{PA1: Communicating the Task and Objectives; Motivating Students for the Activity}

The professor's action had the function of a command (she mentioned what the 
doer should do) and of instruction (she offered information meant for knowledge achievement). It was accompanied by feedforward ( $\mathrm{Ff} 1$ ), which consisted of offering: the model sketch, certain instructions, bibliographical information, description of work stages, and assessment criteria. This action was followed by three responses as a result of the received feedback (students' actions and self-observations [PRs 1a, 1b, 1c]): listening to students' questions (receiving Feedback 2), answering ( $\mathrm{R} \mathrm{Fb1}$; offering feedback), and students' oral completion of the task using feedforward (Ff 2) in order to increase the degree of success for solving the task and to avoid space representation errors. The higher the students' competence level for solving the task was, the less information the professor offered through feedforward at the beginning of the activity.

\section{SR 1: Receiving the Task, the Feedforward and Studying the Materials}

The students' main reaction was positive and followed by positive secondary reactions with the aim to fill in the gap between the information needed to solve the task and the information offered in the task text. They studied the task, model, map, and written information in the course text book while asking their professor or colleagues for help. Related to the task, the students offered feedback to their professor in the form of questions (SR 1a) in front of all their colleagues, running the risk of receiving negative feedback or being ignored. Their questions were proof that students did not have the competence to elaborate sketch maps, that they had deficiencies related to the map components, and that they needed the professor as a source of specific information about their performances, thus confirming Pajares and Graham's (1998) assertions.

Student feedback occurred: in the moment; upon request (Hattie \& Timperley, 2007), it was clarifying, direct, spoken and individual; negative (Murtagh \& Baker, 2009); corrective (Mori, 2011), because it indicated that the task text was not complete enough for the students to understand the task itself; and also positive, as students had asked for information because they were motivated to solve the task (Irving et al., 2011) and because the questions' tone and content did not disturb the initial positive learning environment (Koen et al., 2012). Peer and student feedback was confirmed to be no less reliable or valid than professor feedback (Topping, 2010). The students had two positive secondary reactions: they listened to professor's answers (SR 1b) and instructions (SR 1c); for some of them, the instructions had a feedforward role. Even if nine more new commands had been offered, they could not have been correlated to the actual indicators, which aimed to complete the information in Task V1, nor could they have helped students to realize a better quality product. Still, the text of the task did not include all the necessary pieces of information for the student to solve the task in the best manner. In conclusion, it is difficult for professors to anticipate and always include all instructions in the text of a task that are necessary for all students to be able to solve that task. 


\section{PA 2: Supervising the Task Solving}

Supervision focused on students' actions and their products during the execution process. Students' unconsciously transmitted, non-verbal feedback was received as a response to the requirements, and this was important for establishing and maintaining the relationship with the students (Koen et al., 2012). Thus, aspects related to the solving/learning were identified: not comprehending the task or instructions, knowledge deficiencies, difficulties, order of performing the operations, or work flow. Through internal feedback, unforeseen issues became clear (e.g., the students did not know how to draw the main crest of a mountain).

After looking at the sketches and after performing an on-the-spot assessment, several mistakes were identified: representing the mountains by means of drawing lines around the main peaks; writing mountain names perpendicular to the main peak; writing river names in black capital letters, and so on. By asking students and noticing their work process, the causes of several mistakes were discovered: wrong interpretation of the task; knowledge deficiencies; inattentiveness; wrong model transfer; taking the model from the map instead of from the model sketch; and deficiencies in the model sketch.

Students were observed to behave differently towards the task, and the formative intervention was adapted towards their behavior. According to the correctness of their actions, which were visible in their sketch maps, two categories were identified: correct actions and incorrect actions. Students who performed correct actions needed confirmation, and they were offered positive feedback; the ones who performed incorrect actions needed help in rectifying them. According to their behavior during task solving, students were grouped into four categories: (a) Students who understood the task, knew what to do, how to solve the task, and solved it correctly, but possibly needed positive feedback; (b) students who partially understood the task and asked for the professor's help; (c) students who partially understood the task and asked for their colleagues' help; and (d) students who partially understood the task but did not ask for any help.

After paying attention to the students' actions that required support, the professor had five reactions (PR 2a, 2b, 2c, 2d, 2e) for regulating teaching and learning: listening to questions, answering, and offering instructions (first to draw with a black pencil, then to use color; to use the correction pen); completing the task text; asking for explanations of their mistakes and correcting mistakes; revising or re-doing the papers; and increasing work flow. Oral feedback was used "as a communicative learning tool intended to communicate problems and suggest ways to correct mistakes" (Koen et al., 2012, p. 236). Corrective feedback in front of the seminar group (re-delivered feedback) was preferred to individual feedback so as to emotionally protect those who had made mistakes and also so that all students would hear it. Making students feel "devalued" 
from negative feedback (Murtagh \& Baker, 2009, p. 22) was avoided. Because "feedback can have either positive or negative effects on students' motivation and selfesteem" (Brown, 2004, p. 84; Koen et al., 2012, p. 236), a friendly tone, empathetic feedback language, and encouragement were employed in order to have students realize the needed changes without having negative feelings. Effective feedback, which was described by Fink "as FIDeLity feedback (frequent, immediate, discriminating and delivered lovingly)," should be descriptive and non-judgmental to guide students in learning and to reflect on their learning process (Fink, 2007, p. 15). Feedback "on learning and not on the person," as Wiggins suggested (2004, p. 2), was focused on. Therefore, the supervision was accompanied by oral, frontal, prompt, corrective, and constructive feedback that was specific and appropriate to students' needs.

The role of transmitted answers and instructions differed from one student to another. For the ones who made mistakes, interventions had a feedback function; for the ones who did not realize the actions that interventions referred to or who had not asked for help but needed the respective information to avoid making mistakes, interventions had the feedforward role, as suggested by Goldsmith (2008). Feedforward was offered either when it was unasked for but deemed necessary after noticing students' work manner during task solving, or it was offered in relation to some of their questions. The feedforward was frontal, direct, and verbal. It was specific and concrete because it correlated to the task content and offered the information needed to ensure the correct solution, to avoid mistakes, and to increase work efficiency and product quality. It was simple and clear because it proposed simple actions. It was constructive (for development) because it focused on forming and developing each student's competence to elaborate sketch maps. It was positive emotionally because it displayed confidence in students' task solving, even if some students blamed their lack of talent for drawing. It was confirmed that "using language in a feed-forward way can make a significant difference to students' ultimate achievement” (Koen et al., 2012, p. 237).

In order to avoid the danger where "students may not listen or be distracted or forget what was said" (Koen et al., 2012, p. 236), they were checked to have received the corrective feedback and the feedforward, as well as whether to have responded appropriately.

\section{SR 2: Solving the Task}

Students had three secondary reactions (SR 2a, 2b, 2c.) related to task solving: asking questions, receiving feedback (answers), and receiving feedforward (new instructions). They asked six questions that focused on cartographical details (i.e., How thick/long should the lines be for representing the mountains? Should the lines be straight or a little curved? Where do we place the title?), and they indicated problems in selecting information from the map (i.e., what rivers/neighbors should be represented?). The students who received feedforward accepted the instructions and did not make the same mistakes as their colleagues already had. 


\section{SR 3: Improving the Product}

The students who had made mistakes received and accepted feedback as a result of three secondary reactions (SR 3a, 3b, 3c) through which they self-regulated their learning: they corrected their mistakes, they revised their paper, or they re-did it.

\section{PA 3: Offering the Checklists, as Feedforward Tools}

At the end of the activity, Checklist 1, which had been elaborated before the respective activity, was offered to them by way of e-mail. To sum up, it is difficult for a professor to elaborate on a checklist what to offer students that includes all the necessary information to perfectly solve a task, because the chances of identifying all of the problems that students will cope with are low. In order to increase learning efficiency and product quality, the feedforward tools that professors use during learning activities need an improvement approach after the activity, depending on the learners' competence levels and needs.

\section{SR 4: Self-assessment of the Product}

At home, students assessed their products using Checklist 2. Because the selfassessment activity was not supervised and students' use of the checklist was not researched, no observations can be made about this activity apart from the sketch maps that were received. Because students from both groups had difficulties representing mountain crests, depressions, and rivers, the checklist was concluded to be unable to entirely guide students in their representation of the respective elements and unable to replace all of the professor's interventions.

\section{SR 5: Students' Product Delivery}

Students handed in the sketch maps at the end of the term. This is also called the task-solving delivery.

\section{PA 4: Assessment of Products}

In the students' absence, the assessment tool was used for this. In previous studies (Osaci-Costache et al., 2013; Osaci-Costache et al., 2013a, 2013b; Osaci-Costache et al., 2015), analytical grids had been tested for assessing students' mistakes and competence levels. In the current research, the grid had been conceived for the purpose of showing most objectively the manner of representing a relief feature in a sketch. Although for statistical processing and for the professor's ease of assessment, dichotomist grading (right-wrong) would have been more appropriate, scoring from 0 to 2 (2-correct; 1 partially correct; 0 -incorrect or absent) was offered for each indicator because of their correlation to several elements represented on the map. Even though assessing a sketch map using this tool was more time consuming for the professor, which could discourage 
other professors from using it, it is an efficient guiding tool for realizing the product and for self-assessment, as judged from the students' perspective.

The significant differences between the two groups proved the efficiency of the professors' direct intervention in student activity and the efficiency of the checklist. After analyzing the CG students' results that were obtained from this tool, they were noticed to have had greater difficulties in representing the position and features of geographical elements (rivers, depressions, mountains, etc.) and smaller ones when writing names and titles. The fact that the students in the EG made many mistakes when representing rivers, depressions, and peaks showed us that they did not know these concepts or the relationships between them (i.e., between peak and interfluve, depression and slope, river course and altitude, etc.). The fact that the pre-university education system in Romania seldom has these sketches performed explains these results.

Beginning with the observations of the EG's activity and with assessing the students' results, the questions that had been asked about feedforward at the beginning of this research were answered. "Who needs feedforward?" has been concluded to be the person who learns and solves a task or a problem and needs to organize, keep track of changes, and regulate learning efficiently; it is the person who should know the process that needs to be undergone, the features of the final product, what mistakes to avoid, what models to use, and so on. These persons need feedforward if they cannot solve the task on their own at an acceptable level.

Taking into account its meaning, feedforward has been considered here as a pedagogical intervention through which one who is solving a task or learning is offered before any activity or action all the necessary information that can help one realize the given task according to expectations, or that can help one learn quickly, correctly, and with a minimum of resources. To be efficient, this process should be two-sided: feedforward transmission by the person who is giving the task (in this case, the professor), and the reception and assimilation of the feedforward by the learner (in this case, the student).

Related to feedforward content, in order to be sure that the doer will be able to solve a task correctly, quickly, and with minimum effort, the person giving the task should offer all necessary pieces of information. This relates to: task description (what to do), the process of solving the task (order of stages and steps, how to proceed [what strategies, methods, techniques, and procedures to employ], and what to avoid doing in order to not make mistakes), the necessary means (e.g., tools, apparatus) and their use, criteria for assessing results (behavior or product), and models (demonstrations; correctly, as well as incorrectly, realized products). The feedforward should include specific information about actions and their content ("Represent the mountain peak by uniting the main peaks with a line") without judgments, which have a feedback 
function ("You incorrectly represented the mountain peak"). In addition, as for when to give feedforward, this is thought important to do before solving the task, as well as during solving or whenever needed. This is in contrast to feedback, which is offered after realizing the task or after solving some of its parts.

In order to create and offer feedforward, one may use several methods: enouncing the task, the instructions, and the suggestions concerning work style; discussing the task to enable students' understanding; and dialoguing (answering some students' questions, but offering this information to all students). The two-step sandwich technique (presenting orally or in writing a suggestion/instruction for solving the task and paying attention to whether or not students have solved the task according to the respective suggestion) and a three-step relay technique (identifying incorrect actions or mistakes in the realized product, specifying orally, in front of the seminar group, how to do that action correctly, and paying attention to whether students did or did not do the respective action and whether they did it correctly without making the same mistake) were used.

As tools for providing the feedforward, the following were identified and used: the task text; model sketch, instructions, checklist, and assessment grid. Related to the task, when students were asked to "Elaborate a sketch map of the Eastern Carpathians," the task was noticed to not have the feedforward function. To make the task a feedforward tool, it needed to describe the methodological approach (the stages and steps that the doers should undergo). The text of a task should be adapted to students' knowledge and competence levels. The more detailed and correct the task's text, the better students will understand what they should do; they will know how to do it correctly, quickly, and completely and will need less feedforward and corrective feedback during the activity. Models, including demonstrations, are important for learners, as these have a feedforward function if offered before the activity and are of good quality (i.e., correct and complete). By using them, professors may increase learning efficiency and product quality, provided that students understand them and are able to transfer certain aspects from the task-solving process to new contexts. Instructions also have a feedforward role when offered prior to an activity if they include information needed by the doer. From these, students can know how to do a task more correctly and quickly, and they will be able to self-regulate their learning.

The check list may be an efficient tool for feedforward if it succeeds in guiding selfassessment of the product through its questions. Students who receive a detailed checklist are noted to be able to solve the task more correctly and completely due to the questions, as they can verify, correct, do again, and revise their papers. Nevertheless, checklists are thought to have limited efficiency. During the sketch-map assessment, students were noticed to be unable to correctly assess all elements because they did not have the necessary competence level for such an assessment. A valuable tool for feedforward 
could be an assessment grid, if professors offer it to their students before the activity and if it includes assessment criteria and the indicators for each criterion. Students may use this assessment tool as a guide when solving tasks and realizing their products.

Table 5

Feedforward Categories

\begin{tabular}{ccc}
\hline Assessment criteria & Feedforward categories & Features \\
\hline & - the stimulus is external to the receiver (doer, learn-
\end{tabular}

External er) as it is realized between the source/the sender

Direction of the feedforward and the learner/doer

Internal - the stimulus is transmitted among a person's internal sub-systems

Direct - there are no intermediate links between the source/ sender and the receiver; it is transmitted orally

Number of intermediate links used to transmit the feedforward

Indirect (connected) - regulation is done through several links (sender, receiver 1 , receiver 2 , etc.) and through diverse written tools (task, check list, assessment grid, criteria, and indicators)

The way in which the system Negative

- it diminishes possible mistakes; it indicates unacceptevolution is oriented able features of the result or those that determine a loss in points; how one should not do it as it is wrong Positive - it amplifies the exits; it indicates the positive features of the result and of the actions that need to be done

\begin{tabular}{cl}
\hline Simple & of the result and of the actions that need to be done \\
\hline & - it consists of instructions about simple, easy-to-un- \\
derstand and to-do operations
\end{tabular}

Proposed operation's degree of complexity

Complex

- it focuses on a chain of complicated operations (selection, correlation), difficult to understand and which should be realized in a correct and complete manner by observing a certain order

- of developing/increasing the potential; of clarify-

Constructive

Effect on receivers ing the action and the features of the result; emotional (being confident in ones' success and in solving the task successfully)

\begin{tabular}{|c|c|c|}
\hline & Stabilization & $\begin{array}{l}\text { - it enables the optimum balance (the task is solved as it } \\
\text { should be, with optimum resources and with no stress) }\end{array}$ \\
\hline \multirow{3}{*}{ Number of receivers } & Individual & $\begin{array}{l}\text { - offered to a person, correlated to the task/perfor- } \\
\text { mance of a certain person }\end{array}$ \\
\hline & Collective & $\begin{array}{l}\text { - offered to a small group among other extant groups, } \\
\text { correlated to the task/performance of that group }\end{array}$ \\
\hline & Frontal & $\begin{array}{l}\text { - offered to a group, correlated to the task or to the } \\
\text { individual performances of the people in the group }\end{array}$ \\
\hline \multirow{2}{*}{ Transmission channel } & Written & - through writing \\
\hline & Oral & - through speaking \\
\hline \multirow[t]{2}{*}{ Transmitted content } & General & $\begin{array}{l}\text { - instructions/suggestions that are not correlated to } \\
\text { the task content; these are useless if the doer does } \\
\text { not understand the task nor know how to solve it }\end{array}$ \\
\hline & Specific & $\begin{array}{l}\text { - concrete; correlated to the task content; useful in- } \\
\text { structions for solving the task }\end{array}$ \\
\hline \multirow{2}{*}{ Message clarity } & Clear & - it offers clear, precise instructions for the doer \\
\hline & Ambiguous & - it offers ambiguous instructions for the doer \\
\hline \multirow{2}{*}{$\begin{array}{l}\text { Factors enabling its effi- } \\
\text { ciency }\end{array}$} & Related to the task & - it refers to the task to be solved \\
\hline & Related to the process & $\begin{array}{l}\text { - it refers to the process (the actions) that needs to } \\
\text { be put into practice }\end{array}$ \\
\hline
\end{tabular}


In this research, starting with the observations and with the feedback studies, a series of features were identified for feedforward and were taken into account when realizing an original classification through which this study has filled a gap in the literature (see Table 5). This original classification allows for a more in-depth understanding of feedforward, for its use as a mechanism of increasing learning efficiency and product quality, and for its ability to connect with feedback.

Some limits of feedforward are noticed to be related directly to the receiver's attitude, behavior, and competence: not receiving or partially receiving the feedforward (because of inattentiveness); not understanding, partially understanding, or misunderstanding it (caused by lack of previous knowledge; ambiguous, incomplete, or general feedforward); ignoring the feedforward (considering it as unimportant or neither reading nor studying the recommended material); not accepting it (considering the received information to be incorrect or inappropriate); low transfer capacity of the feedforward to new contexts. Towards the professor's feedforward, students should manifest trust and openness, be receptive to suggestions, dare to ask questions, make an effort to understand the received messages, and ask for instructions from professors and colleagues.

Several limits of feedforward were also observed to be caused by professors: incomplete or ambiguous phrasing of the task, incomplete knowledge of its solution, inability to anticipate possible mistakes or diversity of learners' actions, low ability to supervise the activity, no knowledge about the feedforward mechanism (techniques, means, and tools), unsatisfactory level of communication competence, low empathy, and so on.

\section{Conclusions}

In activities with students, professors use both feedback and feedforward. To increase students' learning efficiency and the quality of results, professors should use feedforward more than feedback because it creates and ensures the necessary conditions for students' correct solving of tasks and because it prevents them from making mistakes. By using feedback, they only correct mistakes. When professors use feedforward that is represented by specific techniques and tools, their students solve the task more quickly, better, and with less resources than in situations where professors offer feedback and students have to re-solve the task in order to achieve the expected results.

Students need their professor's feedforward to improve their learning process and to increase their product quality. In order to offer feedforward, professors should know their tasks very well, their students' features, and the characteristics of their results; they should be empathetic, good observers, and competent communicators, as well as know how to use appropriate feedforward tools and techniques. If professors pay attention to the activity, they will notice some of their students' mistakes and be 
able to use feedforward in a precise and open manner. Thus, they can help students avoid mistakes and will be able to check if students used feedforward constructively. Feedforward is a powerful tool through which professors can determine an increase in learning efficiency and in the quality of the university education system, even if they cannot use feedforward to prevent all the possible mistakes that students make. So that feedforward provides the expected results, it is important that the receiver receives it, understands it, and responds appropriately by self-regulating his or her activity.

\section{References}

Akalın, S., \& Sucuoğlu, B. (2015). Effects of classroom management intervention based on teacher training and performance feedback on outcomes of teacher-student dyads in inclusive classrooms. Educational Sciences: Theory \& Practice, 15(3), 739-758. http://dx.doi. org/10.12738/estp.2015.3.2543

Artvinli, E. (2010a). Configuring geography lessons: Design of a lesson based on action research. Marmara Coğrafya Dergisi, 21, 184-218.

Artvinli, E. (2010b). The contribution of geographic information systems (GIS) to geography education and secondary school students' attitudes related to GIS. Educational Sciences: Theory \& Practice, 10(3), 1277-1292. Retrieved from https://www.researchgate.net/ publication/291520547_article_about_GIS

Artvinli, E. (2012). Integrate geographic skills with active learning in geography: A case of Turkey. Journal of Research and Didactics in Geography (J-READING), O(1), 43-50. http://dx.doi. org/10.4458/1005-06

Baker, D. J., \& Zuvela, D. (2013). Feedforward strategies in the first-year experience of online and distributed learning environments. Assessment \& Evaluation in Higher Education, 38(6), 687697. http://dx.doi.org/10.1080/02602938.2012.691153

Brown, G. T. L. (2004). Measuring attitude with positively packed self-report ratings: Comparison of agreement and frequency scales. Psychological Reports, 94(3), 1015-1024. http://dx.doi. org/10.2466/pr0.94.3.1015-1024

Brown, G. T. L., Harris, L. H., \& Harnett, J. A. (2012). Teacher beliefs about feedback within an assessment for learning environment: Endorsement of improved learning over student well-being. Teaching and Teacher Education, 28(7), 968-978. http://dx.doi.org/10.1016/j.tate.2012.05.003

Cathcart, A., Greer, D., \& Neale, L. (2014). Learner-focused evaluation cycles: Facilitating learning using feedforward, concurrent and feedback evaluation. Assessment \& Evaluation in Higher Education, 39(7), 790-802. http://dx.doi.org/10.1080/02602938.2013.870969

Cervin, A., Eker, J., Bernhardsson, B., \& Årzén, K. E. (2002). Feedback-feedforward scheduling of control tasks. Real-Time Systems, 23(1), 25-53. http://dx.doi.org/10.1023/A:1015394302429

Dulamă, M. E. (2011). Geografie şi didactica geografiei pentru învăţământul primar şi preşcolar [Geography and geography teaching for primary and preschool]. Cluj-Napoca, Romania: Presa Universitară Clujeană.

Dulamă, M. E., \& Ilovan, O. R. (2015). Development of the geography school curriculum in Romania from the $18^{\text {th }}$ century to 1989. Transylvanian Review, 25(Supple. 1), 255-284.

Duncan, N. (2007). 'Feed-forward': Improving students' use of tutors' comments. Assessment \& Evaluation in Higher Education, 32(3), 271-283. http://dx.doi.org/10.1080/02602930600896498

Fink, D. L. (2007). The Power of course design to increase student engagement and learning. $A A C \& U$, Winter, 13-17. Retrieved from http://sites.jmu.edu/flippEDout/files/2013/04/Fink2007.pdf 
Gibbs, G., \& Simpson, C. (2004). Conditions under which assessment supports students' learning. Learning and Teaching in Higher Education, 1, 3-31. http://dx.doi.org/10.1007/978-3-8348-9837-1

Goldsmith, M. (2008). Try feedforward instead of feedback. The Linkage Leader, 1-5. Retrieved from http://www.linkageanz.com.au/uploads/pdf/Marshall_Goldsmith_Try_Feedforward_Instead_of_ Feedback_1102\%5B1\%5D.pdf

Hattie, J., \& Timperley, H. (2007). The power of feedback. Review of Educational Research, 77(1), 81-112. http://dx.doi.org/10.3102/003465430298487

Hernandez, R. (2012). Does continuous assessment in higher education support student learning? Higher Education, 64, 489-502. http://dx.doi.org/10.1007/s10734-012-9506-7

Higgins, R., Hartley, P., \& Skelton, A. (2001). Getting the message across: The problem of communicating assessment feedback. Teaching in Higher Education, 6(2), 269-274. http:// dx.doi.org/10.1080/13562510120045230

Huang, G. B. (2003). Learning capability and storage capacity of two-hidden-layer feedforward networks. Neural Networks, IEEE Transactions on Neural Networks, 14(2), 274-281. http:// dx.doi.org/10.1109/TNN.2003.809401

Ip, E., \& Kahn, J. M. (2007). Feedforward carrier recovery for coherent optical communications. Journal of Lightwave Technology, 25(9), 2675-2692. http://dx.doi.org/10.1109/JLT.2007.902118

Irving, S., Harris, L., \& Peterson, E. (2011). 'One assessment doesn't serve all the purposes' or does it? New Zealand teachers describe assessment and feedback. Asia Pacific Education Review, 12(3), 413-426. http://dx.doi.org/10.1007/s12564-011-9145-1

Klonari, A., \& Mandrikas, A. (2014). Experiential in-service teachers' training for the pilot of the new geography curriculum in Greece: A different experience with tangible results. Review of International Geographical Education Online (RIGEO), 4(2), 139-154. Retrieved from http:// www.rigeo.org/vol4no2/Number2Summer/RIGEO-V4-N2-4.pdf

Koen, K., Bitzer, E. M., \& Beets, P. A. D. (2012). Feedback or feedforward? A case study in one higher education classroom. Journal of Social Sciences, 32(2), 231-242. Retrieved from http:// www.krepublishers.com/02-Journals/JSS/JSS-32-0-000-12-Web/JSS-32-2-000-12-Abst-PDF/ JSS-32-2-231-12-1240-Koen-M/JSS-32-2-231-12-1240-Koen-M-Tx[11].pdf

Lyster, R., \& Ranta, L. (1997). Corrective feedback and learner uptake. Studies in Second Language Acquisition, 19, 37-66. Retrieved from http://people.mcgill.ca/files/roy.lyster/Lyster Ranta1997_SSLA.pdf

Mori, R. (2011). Teacher cognition in corrective feedback in Japan. System, 39, 451-467. http:// dx.doi.org/10.1016/j.system.2011.10.014

Murtagh, L., \& Baker, N. (2009). Feedback to feed forward: Student response to tutors' written comments on assignments. Practitioner Research in Higher Education, 3(1), 20-28. Retrieved from http://194.81.189.19/ojs/index.php/prhe/article/viewFile/30/28

Osaci-Costache, G. (2008). Cartografie [Cartography]. Bucharest, Romania: Editura Universitară.

Osaci-Costache, G., Cocoş, O., \& Cocoş, A., (2015). Assessing students' competence in developing choropleth maps combined with diagram maps. Romanian Review of Geographical Education, 4(2), 57-76. Retrieved from http://rrge.reviste.ubbcluj.ro/Arhive/Art\%20pdf/v4,n2,2015/4\%20 gabriela.pdf

Osaci-Costache, G., Dulamă, M. E, Alexandru, D., \& Voitovici, M. R. (2013). Forming and assessing the competence to elaborate touristic plans. PedActa, 3(2), 97-114. Retrieved from http://padi.psiedu.ubbcluj.ro/pedacta/article_3_2_10.pdf

Osaci-Costache, G., Dulamă, M. E., \& Ilovan, O. R. (2013a). Forming and assessing the competence to elaborate topographic profiles. Studia Universitas Babeş-Bolyai Geographia, 48(2), 199-220. 
Osaci-Costache, G., Dulamă, M. E., \& Ilovan, O. R. (2013b). Geography university students' competence to elaborate column charts: A case study for Romania. Review of International Geographical Education Online, 3(2), 163-188. Retrieved from http://www.rigeo.org/vol3no2/ RIGEO-V3-N2-4.pdf

Pajares, M. F., \& Graham, L. (1998). Formalist thinking and language arts instruction: Teachers' and students' beliefs about truth and caring in the teaching conversation. Teaching \& Teacher Education, 14(8), 855-870.

Peterson, E. R., \& Irving, S. E. (2008). Secondary school students' conceptions of assessment and feedback. Learning and Instruction, 18(3), 238-250. http://dx.doi.org/10.1016/j. learninstruc.2007.05.001

Şencan, H., \& Karabulut, A. T. (2015). Monitoring of educational performance indicators in higher education: A comparison of perceptions. Educational Sciences: Theory \& Practice, 15(2), 359376. http://dx.doi.org/10.12738/estp.2015.2.2426

Shute, V. J. (2008). Focus on formative feedback. Review of Educational Research, 78, 153-189. http://dx.doi.org/10.3102/0034654307313795

Topping, K. J. (2010). Peers as a source of formative feedback. In H. L. Andrade \& G. J. Cizek (Eds.), Handbook of formative assessment (pp. 61-74). New York, NY: Routledge.

Tsao, H., \& Hodges, P. W. (2007). Immediate changes in feedforward postural adjustments following voluntary motor training. Experimental Brain Research, 181(4), 537-546. http:// dx.doi.org/10.1007/s00221-007-0950-Z

Van Rullen, R., \& Koch, C. (2003). Visual selective behavior can be triggered by a feedforward process. Journal of Cognitive Neuroscience, 15(2), 209-217. http://dx.doi. org/10.1162/089892903321208141

Vávra, J. (2014). Cramming facts and thinking concepts: Instance of preparation of student geography teachers in Liberec. Review of International Geographical Education Online (RIGEO), 4(3), 261-280. Retrieved from http://www.rigeo.org/vol4no3/Number3Winter/RIGEO-V4-N3-4.pdf

Wiggins, G. (2004). Assessment as feedback. Retrieved from http://education.jhu.edu/PD/ newhorizons/strategies/topics/Assessment\%20Alternatives/wiggins.htm 